\title{
Mechanisms of tumor-related brain edema
}

\author{
WALter STUMmer, M.D. \\ Department of Neurosurgery, Düsseldorf, Germany
}

\begin{abstract}
$\checkmark$ Cerebral edema contributes strongly to symptoms associated with brain tumors. Although the introduction of corticosteroids has greatly simplified treatment of patients with newly diagnosed tumors, these drugs are associated with marked side effects during the long-term treatment that is often necessary in the recurrences. Therefore, a better understanding of mechanisms related to the evolution and clearance of tumor-related edema with the aid of modern imaging and molecular methodology is clearly necessary. Recently, researchers have focused on molecular mechanisms of edema development and have demonstrated alternative routes-such as the inhibition of vascular endothelial growth factor receptor inhibitors - to be explored for treating edema. In this review the author focuses on established and current concepts regarding the pathophysiology of cerebral edema and its treatment.
\end{abstract}

\begin{abstract}
KEY WORDS • brain tumor • morphology • pathophysiology • therapy • vasogenic edema
\end{abstract}

\section{$\mathrm{E}$} DEMA ASSOCIATED WITH brain tumors plays a major role in determining symptoms caused by cerebral tumors. ${ }^{70}$ Not only does edema cause additional mass effect, often exceeding the mass induced by the tumor itself and resulting in increased intracranial pressure, it also leads to neurological disturbances by disrupting tissue homeostasis and reducing local blood flow. ${ }^{27,51,91}$ Nearly all focal lesions, including primary and metastatic tumors, abscesses, encephalitides, and radionecroses, produce vasogenic edema. Although steroids have facilitated the management of edema in patients with newly diagnosed brain tumors, long-term therapy of tumor-associated edema remains an important issue in the context of recurrent malignant gliomas or lesions treated using radiosurgery or radiotherapy rather than resection. Nevertheless, authors of only a few studies have specifically addressed clinical management issues of cerebral edema. Furthermore, viewing tumor-associated edema as a single entity is probably not justified. For example, in contrast to edema surrounding metastases (Fig. 1) or meningiomas, peritumoral edema associated with high-grade gliomas (Fig. 2) is characterized by extensive infiltration of tumor cells. Types of peritumoral edema may therefore be distinguishable, depending on histopathological and clinical properties. Adopting a more differentiated view would likely lead to improved strategies of treatment and diagnosis for brain tumors accompanied by peritumoral edema.

Abbreviations used in this paper: $\mathrm{BBB}=$ blood-brain barrier; COX-2 = cyclooxygenase- 2 ; $\mathrm{CT}=$ computed tomography; $\mathrm{DT}=$ diffusion tensor; GBM = glioblastoma multiforme; $M R=$ magnetic resonance; $\mathrm{NO}=$ nitric oxide; $\mathrm{NOS}=\mathrm{NO}$ synthase; $\mathrm{VEGF}=$ vascular endothelial growth factor; VEGFR = VEGF receptor; $\mathrm{WHO}=$ World Health Organization..
In this review I summarize the established and new concepts regarding the pathophysiology of peritumoral edema based on morphological and molecular findings, as well as modern imaging.

\section{Capillary Ultrastructure in Brain Tumors}

Edema associated with brain tumors is considered to be vasogenic and thus pathophysiologically similar to edema due to brain injury or cerebral abscesses. The primary disturbance is at the level of the microvasculature. ${ }^{50} \mathrm{In}$ simplified terms, the tight junctions that form the BBB protect the brain's interstitial space from plasma extravasation under normal conditions, as there is no lymphatic system within the brain. In vasogenic edema, vascular permeability is increased. Under normal conditions a "sink effect" is provided by the ventricles and subarachnoid cerebrospinal fluid to allow steady circulation and replenishment of the extracellular space. This sink effect is overwhelmed in vasogenic edema, resulting in extracellular fluid accumulation.

Edema resulting from tumors must be distinguished from cytotoxic edema, for instance as a consequence of hypoxia of cytotoxic origin, resulting from cellular swelling after breakdown of transmembraneous ion gradients due to energy depletion. ${ }^{40,50}$ These two types of brain edema were first differentiated by Klatzo ${ }^{38}$ in the 1960s.

Metastatic and nonglial brain tumors produce angiogenic factors that promote capillary formations with marked ultrastructural abnormalities. In nonglial brain tumors, pinocytic vesicles are observed more frequently, and the basal laminae are more irregular. ${ }^{80}$ Glial tumors also lack a normal BBB. In a spheroid model of glioma in 




FIG. 1. Axial T2-weighted MR image showing the typical aspect of edema in cerebral metastases in a patient with pulmonary carcinoma.

rats, the mass of tumor vessels display either abnormal tight junctions or fenestrations. ${ }^{86}$ In human gliomas endothelial cell junctions of capillaries appear either short or elongated, and the endothelia display hyperplasia, surface infolding of endothelial cells, irregular basal laminae, and large extravascular spaces in ultrathin and freeze-fracture replicas. ${ }^{80}$ Proliferated endothelia in malignant gliomas are further characterized by fenestrations, defective tight junctions, increased numbers of pinocytic vesicles, and incomplete ensheathment of endothelial cells by the basal membrane. Although vascular permeability cannot be measured directly in tumor specimens from humans, it can be inferred that tumor vessels-which are derived from previously existing vessels-demonstrate structural abnormalities that explain their lost barrier functions, allowing leakage of plasma exudate into the surrounding brain. $28,44,45,55$

On a molecular level, morphologically disrupted tight junctions in newly formed brain tumor capillaries are associated with a paucity or lack of proteins such as occludin, claudins, or the junctional adhesion molecule. These entities are all part of the molecular composition of tight junctions in the healthy brain. ${ }^{15,18,19,29,52,64}$ These transmembrane proteins bind intracellular proteins such as $\mathrm{ZO}-$ 1 and ZO-2. Binding results in the coupling of tight junctions to the cytoskeleton of endothelial cells. It has been suggested that a decrease in expression or function of these tight junction proteins leads to opening of the junction and to the formation of edema. This hypothesis is supported by findings from several studies. For example, only low levels of claudin-1 were found to be expressed in microvessels from GBM, whereas high-grade gliomas (WHO Grades III and IV) did not express functional occludin. ${ }^{22,64}$

\section{The Role of VEGF}

In addition to structurally abnormal tumor vessels within the tumor itself, the vessels in neighboring tumor tissue may be affected by infiltrating tumor cells and show clear ultrastructural changes, such as elongated junctional clefts (unfused regions) and an increase in the density of en-

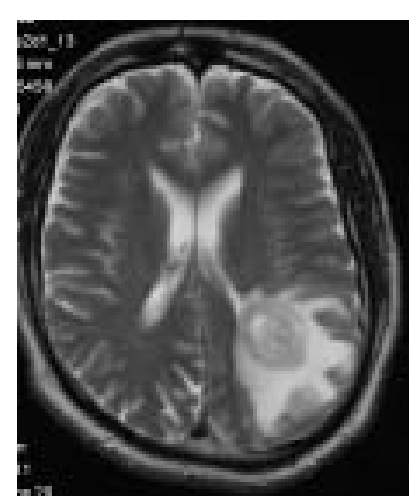

FIG. 2. Axial T2-weighted MR image showing cerebral edema in a patient with GBM.

dothelial vesicles, depending on the density of infiltrating cells. These changes were also observed when vessels were not immediately invested by tumor cells, suggesting the presence of cytokines, which spread into peritumoral tissue and disrupt normal vascular morphology. ${ }^{85}$

One cytokine that has been under close investigation is VEGF. Paracrine signal pathways involving VEGF may be involved in the generation of peritumoral edema. This cytokine was originally described as vascular permeability factor and is involved in angiogenesis and vascular permeability ${ }^{78}$ The VEGF binds to endothelial cells via the tyrosine kinase receptors flt-1 (VEGFR-1) and Flk-1/ KDR (VEGFR-2). Both are predominantly expressed on endothelial cells. ${ }^{16,56}$ Vascular endothelial growth factor appears to be involved in tumorigenesis, neovascularization, and edema production. ${ }^{48}$ Apart from its mitogenic and chemotactic influence on endothelial cells, VEGF potently enhances permeability of endothelium and is approximately 1000 times more potent than histamine. ${ }^{12,13}$ Similar to histamines and other mediators, VEGF exerts its effects on venules and small capillaries and acts immediately on endothelial cells, but not on smooth muscle cells, fibroblasts, or neutrophils, through mobilization of intracellular calcium. ${ }^{48}$ Vascular endothelial growth factor may impair the function of occludin by phosphorylation of this protein, with consecutive opening of tight junctions. ${ }^{63}$ Possibly, VEGF induces fenestration of the endothelium and enhances capillary permeability through this mechanism. ${ }^{72}$ On the other hand, upregulation of VEGF has been observed in brain tumors commonly associated with edema, such as GBMs, meningiomas, and metastases. ${ }^{7,61,65,88}$ In patients with meningioma, there is a correlation between the presence or absence of peritumoral edema and levels of VEGF mRNA. ${ }^{22,37}$ Meningiomas with pronounced edema displayed higher levels of VEGF protein staining. ${ }^{68}$

Nevertheless, in the clinical situation clear correlations between VEGF and brain tumor grade or prognosis are missing. ${ }^{48}$ Therefore, the presence of edema does not automatically imply a high grade of malignancy. For example, secretory meningiomas are benign meningiomas (WHO Grade I) and display extensive edema surrounding the tumor. ${ }^{61,65,75}$ Meningiomas are not considered severely hypoxic, and other factors that upregulate VEGF may be involved, such as platelet-derived growth factor, epidermal growth factor, and estrogens ${ }^{48,53,83}$ Edema in menin- 
giomas has also been associated with morphological factors, including tumor size and histological subtype, whereby transitional and meningotheliomatous types tend to produce more edema. ${ }^{21}$ Furthermore, invasion of adjacent brain by meningioma has been related to the presence of edema. ${ }^{8,32,49}$ The invading meningioma phenotype disrupts the bordering arachnoid, possibly providing a route for the spread of edema mediators, including VEGF. These mediators may cause not only the propagation of edema but also the proliferation of new blood vessels, thus explaining the high correlation between pial blood supply and peritumoral brain edema.

In contrast, VEGF expression in human gliomas is related to their degree of malignancy. Low-grade gliomas express low levels of VEGF, whereas progression of lowgrade gliomas into malignant gliomas is associated with an up to 50-fold increase in VEGF mRNA levels. ${ }^{66}$ Increased VEGF expression has been correlated with vascular permeability in situ. ${ }^{46}$ The expression of VEGF is largely restricted to perinecrotic cells, suggesting that hypoxia regulates its expression in high-grade gliomas. ${ }^{82}$ Conversly, pilocytic astrocytomas (WHO Grade I) have an excellent prognosis while displaying high levels of VEGF mRNA. ${ }^{41}$ Regulation of VEGF in these tumors may be the consequence of factors other than hypoxia, such as a loss of function of the p53 tumor suppressor gene. ${ }^{58}$

\section{Other Mechanisms Under Investigation}

Apart from VEGF, other factors implicated in edema formation related to brain tumors include arachidonic acid metabolites and NO. Elevated levels of leukotriene C4 (produced via the lipoxygenase pathway) have been found in GBM and in adjacent edematous brain tissue in correlation with the amount of peritumoral edema. ${ }^{9,59}$ In a rat glioma model, microglia, which infiltrates brain tumors, was demonstrated to be a major source of prostaglandin E2 production through the COX-2 pathway. ${ }^{3}$ The COX-2and lipoxygenase-derived biologically active lipid mediators are thought to promote tumorigenesis and peritumoral brain edema. ${ }^{59}$

Nitric oxide has been identified as a specific mediator of vasodilation and tumor blood flow in primary brain tumors and has also been investigated in the context of brain tumor-associated edema. The concept involves induction of NOS isoenzymes as a result of tumor hypoxia. Inducible NOS II is expressed in tumor-infiltrating microglia and macrophages. However, a correlation between the quantity and expression of NOS has not been demonstrated in primary brain tumors, whereas a specific edemamodulating role of $\mathrm{NO}$ in cerebral metastasis has been considered. ${ }^{10}$ In this context, it appears that VEGFinduced edema formation may occur via the synthesis and release of NO. ${ }^{54}$ Other vasogenic substances that may contribute to the pathophysiology of tumor-related edema are serotonin, thromboxanes, and platelet-activating factor. ${ }^{20,30}$

Macrophages may also be involved in edema accumulation because the degree of macrophage infiltration seen on immunoperoxidase staining correlates with the extent of peritumoral edema ${ }^{81}$ This has been taken to suggest that secretory products of macrophages might contribute to edema formation associated with brain tumors.
An additional hypothesis with possible implications for the formation and regulation of brain edema has recently emerged after the discovery of the aquaporin protein family. Aquaporins are small, hydrophobic, integral membrane proteins that are expressed in all living organisms and play critical roles in controlling the water flow into and out of cells. In the brain, aquaporin-4 is expressed in endothelial astrocytic foot processes. Aquaporin-4 is highly upregulated in high-grade gliomas. ${ }^{60,74}$ As yet, however, it is undetermined whether this upregulation results in increased edema formation or in enhanced clearance of edema. Nevertheless, modulation of the expression and/or function of aquaporins may provide novel therapeutic options for reducing brain tumor-associated edema.

\section{Bulk Flow of Edema}

One of the first pathophysiological aspects of tumorassociated edema to be studied extensively was bulk flow. Interest in bulk flow has recently been revived due to the development of convection-enhanced delivery as a treatment modality for malignant gliomas, as well as to advances in neuroradiology, such as DT imaging. Historically, the introduction of CT in the 1970s advanced the understanding of edema propagation and resolution in patients. Around that time it was established that tumorassociated edema propagates by bulk flow rather than by simple diffusion. Due to bulk flow, small pressure gradients, such as the gradient between gray and white matter, are sufficient to prevent or redirect the spreading of edema. White matter has a lower resistance than the more densely packed gray matter; therefore, edema tends to propagate in fingerlike projections throughout the white matter. ${ }^{69}$ This phenomenon has been confirmed with mathematical models based on CT measurements. ${ }^{1}$ Computed tomography has also been used to measure the speed of extravasation of intravenous contrast material. ${ }^{34}$ Based on a spherical model of edema propagation from the lesion, the formation rate of edema fluid was calculated as 0.5 to $3.2 \mathrm{ml} /$ hour and the speed of edema fluid spreading to 1.9 $\mathrm{mm} /$ hour. In a patient with a metastasis, fluid was produced at a rate of $3.9 \mathrm{ml} /$ hour, which led to an edematous volume in the brain of $87.3 \mathrm{ml}^{70}$

In these key analyses it was recognized that the volume of edema depends not only on the rate of edema production but also on the rate of resorption of extravasated fluid. Clearance of extravasated fluid was considered to be due to the hydrostatic pressure responsible for the bulk flow of edema fluid pushing the fluid away from the lesion until it is cleared primarily in the ventricular ${ }^{71}$ and, to a lesser extent, the subarachnoid cerebrospinal fluid..$^{95}$ Other clearance mechanisms include absorption through the subarachnoid space, which has been demonstrated to be independent of intracranial pressure ${ }^{95}$ or - to a limited extent - the resorption of extravasated proteins by astrocytic cells. This mechanism decreases the extracellular oncotic pressure and thus limits propagation, contributing to the resolution of edema.. ${ }^{24}$ Finally, there is a limited amount of absorption by local capillaries in the edematous tissue, which can be quantified (authors of one study found this rate to be $\left.0.0086 \mathrm{ml} / \mathrm{hr} / \mathrm{cm}^{3}\right) .{ }^{24}$ Work involving edema formation and resolution before and after dexamethasone treatment has shown that the drug acts by de- 
creasing edema formation rather than by increasing its resolution. ${ }^{33}$

The more recent emergence of MR imaging as a diagnostic tool has corroborated the earlier CT findings and has given access to additional information regarding the pathophysiology of tumor-related edema. For instance, by measuring changes in relaxation time (T1), the extracellular distribution volume $\left(\mathrm{V}_{\mathrm{d}}\right)$ and capillary permeability expressed as the unidirectional transport rate constant $\left(\mathrm{K}_{\mathrm{i}}\right)$ can be calculated for various tumor types. Meningiomas have a higher $\mathrm{K}_{\mathrm{i}}$ than gliomas or metastases. After treatment with dexamethasone, the $\mathrm{K}_{\mathrm{i}}$ decreases by $52 \%$ in gliomas and metastases, but only by $4 \%$ in meningiomas. ${ }^{2}$ Magnetic resonance imaging has also been used to measure cerebral blood flow, cerebral blood volume, and brain-tumor barrier permeability. Changes in perfusion have been studied using dynamic perfusion-weighted MR imaging. Relative regional cerebral blood volume and flow were almost $50 \%$ lower in peritumoral brain edema than in the contralateral white matter in patients with meningiomas. ${ }^{91}$ Furthermore, the positive effects of dexamethasone administration on cerebral blood flow and BBB permeability have been quantified by MR imaging. ${ }^{4,62}$

More novel assessments of peritumoral edema involve DT imaging for making visible and analyzing apparent water diffusivity in tissues in vivo. ${ }^{5,39,57}$ Using this technique, investigators have found greater apparent water diffusivity in high-grade gliomas, whereas the anisotropy (the property of being directionally dependent) in these lesions was comparable to that of edema in other tumors (low-grade gliomas, metastases, and meningiomas). This observation was taken to imply that there are two distinct types of peritumoral edema: edema associated with highgrade gliomas and edema associated with low-grade gliomas or nonglial tumors, despite the lack of a signal intensity difference between these two edema groups on T2-weighted MR imaging. Water movement in areas of edema, predominantly in the extracellular spaces, was less restricted in high-grade gliomas, a phenomenon that likely reflected the destruction of the extracellular matrix ultrastructure by malignant cell infiltration and, consequently, greater water diffusion. On the basis of these observations, it has been argued that DT imaging could be used as a clinical tool for differentiating high-grade gliomas and for evaluating the extent of cellular infiltration.

Correlative studies on the histopathological characteristics of malignant gliomas and imaging findings have demonstrated a high degree of concordance between the T2 signal abnormality on MR images as an indicator of edema and tumor cell infiltration. ${ }^{93}$ Fractional anisotropy seen on DT images correlated with the density of tumor cell infiltration. ${ }^{84}$ Therefore, a strong association between edema propagation and malignant cell infiltration has been shown in these studies.

This understanding of cell migration and fluid flow dynamics within tumor and brain interstitial space has gained attention in the context of convection-enhanced delivery, which has been developed as a novel instrument for transporting drugs to infiltrating malignant glioma cells. ${ }^{25}$ Therefore, methods of assessment and visualization of fluid movements within the brain, such as DT imaging, will be of future interest, not only for optimizing edema treatment, but also for optimizing brain tumor therapy. ${ }^{76}$

\section{Management of Brain Tumor Edema}

The mainstay of therapy of brain tumor-related edema is corticosteroids for both nonglial and glial tumors. These drugs have been used since the $1960 \mathrm{~s}^{36,73}$ and have led to a remarkable decline in perioperative mortality and morbidity rates. The preferred compound is dexamethasone due to its low mineralocorticoid effects in comparison with other corticosteroids. With long-term use, however, the positive action is counterweighted by deleterious side effects such as immunosuppression, weight gain, gastrointestinal problems, osteoporosis, myopathy, and an enhanced risk of deep vein thrombosis and pulmonary embolism. The mechanisms of action of corticosteroids are still unclear. Corticosteroids lead to a decrease in the rate of edema formation without effecting clearance, ${ }^{33}$ which appears to occur within 1 hour after administration, as demonstrated by reductions in capillary permeability. ${ }^{79} \mathrm{Al}-$ though data have been presented showing that dexamethasone acts by reducing the expression of VEGF, ${ }^{26,47}$ this agent may act by interfering with VEGF action on the target endothelial cell. ${ }^{55}$ In cultured endothelial cells, VEGF has been shown to increase intracellular $\mathrm{Ca}^{2+}$, which has been associated with cytoskeletal rearrangement. Dexamethasone appears to block this influx. ${ }^{14}$ Furthermore, in peripheral blood vessels, the increase in vascular permeability seen after intradermal injection of VEGF is inhibited by systemic administration of dexamethasone, acting through the glucocorticoid receptor. ${ }^{11,26}$

In Western Europe, neurooncologists try to treat brain tumor-induced edema and to overcome corticosteroid dependency as well as corticosteroid-related side effects by administering boswellic acids (H15). These are phytotherapeutic agents that are believed to inhibit edema formation and even tumor growth in patients with malignant gliomas. ${ }^{35,87}$

A number of additional experimental approaches are being pursued at the moment; some are still in the preclinical stage, and some are in early clinical studies. Thrombin has been investigated as a possible target of antiedema strategies. An enzyme involved in the coagulation cascade, thrombin has also been implicated in brain edema formation, angiogenesis, and cell proliferation. Argatroban, a thrombin antagonist, was shown to reduce edema, tumor growth, and tumor-related neurological deficits in rat glioma models. ${ }^{23,31}$

Attention has also been directed toward corticotropinreleasing factor, a polypeptide that regulates adrenocorticotropin hormone release from the pituitary gland, which in turn regulates hydrocortisone secretion from the adrenal gland. Corticotropin-releasing factor has also been studied in conjunction with intracerebral gliomas and has been found to reduce BBB permeability in a tumor model ${ }^{90}$ and to improve neurological function in patients suffering brain metastasis. ${ }^{92}$

Due to its implication in the generation of brain tumor-related edema, selective inhibition of VEGF has been explored, for instance by the antiangiogenic drug SU5416 (semaxanib), a small molecule that selectively inhibits tyrosine kinase activity of the VEGFR Flk-1/ KDR. This drug has been associated with prolonged survival in rats with intracerebral gliosarcoma and increased necrosis while reducing vascularity. ${ }^{89}$ Similar observations 
were made in nude mice with human GBM xenografts. ${ }^{77}$ Although promising activity in neoplastic disease outside the brain has been demonstrated in patients, ${ }^{17,43,96}$ the value of semaxanib in brain edema treatment is unclear. On the other hand, the pan-VEGFR inhibitor AZD2171 has to date shown efficacy in normalizing vasculature and alleviating edema in patients with GBM, ${ }^{6}$ giving proof of the principle of this concept and endorsing further studies.

Another class of compounds has recently received some attention, the inhibitors of COX2. In one study, the COX-2 inhibitor SC-236 has demonstrated a prolongation of survival similar to dexamethasone when administered in rats with intracerebral gliosarcomas. ${ }^{67}$ Similarily, the diffusion of contrast medium into adjacent brain was attenuated in rats with intracerebral C6-gliomas after pretreatment with rofecoxib, another selective COX-2 inhibitor. Rofecoxib was as effective as dexamethasone in these experiments. A mode of action for COX-2 inhibitors might be the reduction of transcription factor Sp1's DNA binding and transactivating activity, resulting in less production of VEGF.94

\section{Future Directions}

To date, VEGFR antagonists, COX-2 inhibitors, boswellic acid, and other experimental therapeutic agents have not been shown to be superior to corticosteroids in the management of brain tumor-related edema; furthermore, careful assessments are required. A better understanding of different types of tumor edema related to different pathological entities and their molecular mechanisms may open the way to targeted therapies. Improved understanding of the molecular mechanisms controlling BBB permeability will allow manipulation of this permeability for improving therapy for malignant brain tumors with drugs that, under physiological circumstances, cannot cross this important barrier.

\section{References}

1. Aaslid R, Groger U, Patlak CS, Fenstermacher JD, Huber P, Reulen HJ: Fluid flow rates in human peritumoral oedema. Acta Neurochir Suppl (Wien) 51:152-154, 1990

2. Andersen C: The effect of glucocorticoids in the normal cerebral hemisphere of brain tumor patients. Acta Neurol Scand 98:433-438, 1998

3. Badie B, Schartner JM, Hagar AR, Prabakaran S, Peebles TR, Bartley B, et al: Microglia cyclooxygenase-2 activity in experimental gliomas: possible role in cerebral edema formation. J Clin Cancer Res 9:872-877, 2003

4. Bastin ME, Carpenter TK, Armitage PA, Sinha S, Wardlaw JM, Whittle IR: Effects of dexamethasone on cerebral perfusion and water diffusion in patients with high-grade glioma. AJNR Am J Neuroradiol 27:402-408, 2006

5. Bastin ME, Sinha S, Whittle IR, Wardlaw JM: Measurements of water diffusion and $\mathrm{T} 1$ values in peritumoral oedematous brain. Neuroreport 13:1335-1340, 2002

6. Batchelor TT, Sorensen AG, di Tomaso E, Zhang WT, Duda DG, Cohen KS, et al: AZD2171, a pan-VEGF receptor tyrosine kinase inhibitor, normalizes tumor vasculature and alleviates edema in glioblastoma patients. Cancer Cell 11:83-95, 2007

7. Berkman RA, Merrill MJ, Reinhold WC, Monacci WT, Saxena A, Clark WC, et al: Expression of the vascular permeability factor/vascular endothelial growth factor gene in central nervous system neoplasms. J Clin Invest 91:153-159, 1993
8. Bitzer M, Wockel L, Morgalla M, Keller C, Friese S, Heiss E, et al: Peritumoral brain oedema in intracranial meningiomas: influence of tumor size, location and histology. Acta Neurochir (Wien) 139:1136-1142, 1997

9. Black KL, Hoff JT, McGillicuddy JE, Gebarski SS: Increased leukotriene $\mathrm{C} 4$ and vasogenic edema surrounding brain tumors in humans. Ann Neurol 19:592-595, 1986

10. Broholm H, Rubin I, Kruse A, Braendstrup O, Schmidt K, Skriver EB, et al: Nitric oxide synthase expression and enzymatic activity in human brain tumors. Clin Neuropathol 22: 273-281, 2003

11. Bruce JN, Criscuolo GR, Merrill MJ, Moquin RR, Blacklock JB, Oldfield EH: Vascular permeability induced by protein product of malignant brain tumors: inhibition by dexamethasone. J Neurosurg 67:880-884, 1987

12. Connolly DT: Vascular permeability factor: a unique regulator of blood vessel function. J Cell Biochem 47:219-223, 1991

13. Criscuolo GR: The genesis of peritumoral vasogenic brain edema and tumor cysts, a hypothetical role for tumor-derived vascular permeability factor. Yale J Biol Med 66:277-314, 1993

14. Criscuolo GR, Lelkes PI, Rotrosen D, Oldfield EH: Cytosolic calcium changes in endothelial cells induced by a protein product of human gliomas containing vascular permeability factor activity. J Neurosurg 71:884-891, 1989

15. Davies DC: Blood-brain barrier breakdown in septic encephalopathy and brain tumors. J Anat 200:639-646, 2002

16. de Vries C, Escobedo JA, Ueno H, Houck K, Ferrara N, Williams LT: The fms-like tyrosine kinase, a receptor for vascular endothelial growth factor. Science 255:989-991, 1992

17. Fiedler W, Mesters R, Tinnefeld H, Loges S, Staib P, Duhrsen $\mathrm{U}$, et al: A phase 2 clinical study of SU5416 in patients with refractory acute myeloid leukemia. Blood 102:2763-2767, 2003

18. Furuse M, Fujita K, Hiiragi T, Fujimoto K, Tsukita S: Claudin1 and -2 : novel integral membrane proteins localizing at tight junctions with no sequence similarity to occludin. J Cell Biol 141:1539-1550, 1998

19. Furuse M, Hirase T, Itoh M, Nagafuchi A, Yonemura S, Tsukita S, et al: Occludin: a novel integral membrane protein localizing at tight junctions. J Cell Biol 123:1777-1788, 1993

20. Gaetani P, Butti G, Chiabrando C, Danova M, Castelli MG, Riccardi A, et al: A study on the biological behavior of human brain tumors. Part I. Arachidonic acid metabolism and DNA content. J Neurooncol 10:233-240, 1991

21. Go KG, Wilmink JT, Molenaar WM: Peritumoral brain edema associated with meningiomas. Neurosurgery 23:175-179, 1988

22. Goldman CK, Bharara S, Palmer CA, Vitek J, Tsai JC, Weiss $\mathrm{HL}$, et al: Brain edema in meningiomas is associated with increased vascular endothelial growth factor expression. Neurosurgery 40:1269-1277, 1997

23. Gorman AM, Hirt UA, Orrenius S, Ceccatelli S: Dexamethasone pre-treatment interferes with apoptotic death in glioma cells. Neuroscience 96:417-425, 2000

24. Groger U, Huber P, Reulen HJ: Formation and resolution of human peritumoral brain edema. Acta Neurochir Suppl 60: 373-374, 1994

25. Hall WA, Sherr GT: Convection-enhanced delivery: targeted toxin treatment of malignant glioma. Neurosurg Focus 20(4): E10, 2006

26. Heiss JD, Papavassiliou E, Merrill MJ, Nieman L, Knightly JJ, Walbridge S, et al: Mechanism of dexamethasone suppression of brain tumor-associated vascular permeability in rats. Involvement of the glucocorticoid receptor and vascular permeability factor. J Clin Invest 98:1400-1408, 1996

27. Hino A, Imahori Y, Tenjin H, Mizukawa N, Ueda S, Hirakawa $\mathrm{K}$, et al: Metabolic and hemodynamic aspects of peritumoral 
low-density areas in human brain tumor. Neurosurgery 26: 615-621, 1990

28. Hirano A, Kawanami T, Llena JF: Electron microscopy of the blood-brain barrier in disease. Microsc Res Tech 27:543-556, 1994

29. Hirase T, Staddon JM, Saitou M, Ando-Akatsuka Y, Itoh M, Furuse M, et al: Occludin as a possible determinant of tight junction permeability in endothelial cells. J Cell Sci 110: 1603-1613, 1997

30. Hirashima Y, Hayashi N, Fukuda O, Ito H, Endo S, Takaku A: Platelet-activating factor and edema surrounding meningiomas. J Neurosurg 88:304-307, 1998

31. Hua Y, Tang LL, Fewel ME, Keep RF, Schallert T, Muraszko $\mathrm{KM}$, et al: Systemic use of argatroban reduces tumor mass, attenuates neurological deficits and prolongs survival time in rat glioma models. Acta Neurochir Suppl 95:403-406, 2005

32. Ide M, Jimbo M, Kubo O, Yamamoto M, Takeyama E, Imanaga $\mathrm{H}$ : Peritumoral brain edema and cortical damage by meningioma. Acta Neurochir Suppl 60:369-372, 1994

33. Ito U, Reulen HJ, Tomita H, Ikeda J, Saito J, Maehara T: A computed tomography study on formation, propagation, and resolution of edema fluid in metastatic brain tumors. Adv Neurol 52:459-468, 1990

34. Ito U, Reulen HJ, Tomita H, Ikeda J, Saito J, Maehara T: Formation and propagation of brain oedema fluid around human brain metastases: a CT study. Acta Neurochir (Wien) 90: 35-41, 1988

35. Janssen G, Bode U, Breu H, Dohrn B, Engelbrecht V, Gobel U: Boswellic acids in the palliative therapy of children with progressive or relapsed brain tumors. Klin Pädiatr 212:189-195, 2000

36. Jelsma R, Bucy PC: The treatment of glioblastoma multiforme of the brain. J Neurosurg 27:388-400, 1967

37. Kalkanis SN, Carroll RS, Zhang J, Zamani AA, Black PM: Correlation of vascular endothelial growth factor messenger RNA expression with peritumoral vasogenic cerebral edema in meningiomas. J Neurosurg 85:1095-1101, 1996

38. Klatzo I: Presidential address. Neuropathological aspects of brain edema. J Neuropathol Exp Neurol 26:1-14, 1967

39. Kono K, Inoue Y, Nakayama K, Shakudo M, Morino M, Ohata $\mathrm{K}$, et al: The role of diffusion-weighted imaging in patients with brain tumors. AJNR Am J Neuroradiol 22:1081-1088, 2001

40. Kucinsky T, Vaterlein O, Glauche V, Fiehler J, Klotz E, Eckert $\mathrm{B}$, et al: Correlation of apparent diffusion coefficient and computed tomography density in acute ischemic stroke. Stroke 33: 1786-1791, 2002

41. Leung SY, Chan AS, Wong MP, Yuen ST, Cheung N, Chung LP: Expression of vascular endothelial growth factor and its receptors in pilocytic astrocytoma. Am J Surg Pathol 21: 941-950, 1997

42. Liebner S, Fischmann A, Rascher G, Duffner F, Grote EH, Kalbacher H, et al: Claudin-1 and claudin-5 expression and tight junction morphology are altered in blood vessels of human glioblastoma multiforme. Acta Neuropathol 100:323-331, 2000

43. Loges S, Tinnefeld H, Metzner A, Jucker M, Butzal M, Bruweleit M, et al: Downregulation of VEGF-A, STAT5 and AKT in acute myeloid leukemia blasts of patients treated with SU5416. Leuk Lymphoma 47:2601-2609, 2006

44. Long DM: Capillary ultrastructure and the blood-brain barrier in human malignant brain tumors. J Neurosurg 32:127-144, 1970

45. Long DM: Capillary ultrastructure in human metastatic brain tumors. J Neurosurg 51:53-58, 1979

46. Machein MR, Kullmer J, Fiebich BL, Plate KH, Warnke PC: Vascular endothelial growth factor expression, vascular volume, and capillary permeability in human brain tumors. Neurosurgery 44:732-741, 1999

47. Machein MR, Kullmer J, Ronicke V, Machein U, Krieg M,
Damert A, et al: Differential downregulation of vascular endothelial growth factor by dexamethasone in normoxic and hypoxic rat glioma cells. Neuropathol Appl Neurobiol 25: 104-112, 1999

48. Machein MR, Plate KH: VEGF in brain tumors. J Neurooncol 50:109-120, 2000

49. Mantle RE, Lach B, Delgado MR, Baeesa S, Belanger G: Predicting the probability of meningioma recurrence based on the quantity of peritumoral brain edema on computerized tomography scanning. J Neurosurg 91:375-383, 1999

50. Marmarou A, Portella G, Barzo P, Signoretti S, Fatouros P, Beaumont A, et al: Distinguishing between cellular and vasogenic edema in head injured patients with focal lesions using magnetic resonance imaging. Acta Neurochir Suppl 76: 349-351, 2000

51. Marmarou A, Takagi H, Shulman K: Biomechanics of brain edema and effects on local cerebral blood flow. Adv Neurol 28:345-358, 1980

52. Martin-Padura I, Lostaglio S, Schneemann M, Williams L, Romano M, Fruscella P, et al: Junctional adhesion molecule, a novel member of the immunoglobulin superfamily that distributes at intercellular junctions and modulates monocyte transmigration. J Cell Biol 142:117-127, 1998

53. Maxwell M, Galanopoulos T, Hedley-Whyte ET, Black PM, Antoniades $\mathrm{HN}$ : Human meningiomas co-express plateletderived growth factor (PDGF) and PDGF-receptor genes and their protein products. Int J Cancer 46:16-21, 1990

54. Mayhan WG: VEGF increases permeability of the blood-brain barrier via a nitric oxide synthase/cGMP-dependent pathway. Am J Physiol 276:C1148-C1153, 1999

55. Merrill MJ, Oldfield EH: A reassessment of vascular endothelial growth factor in central nervous system pathology. J Neurosurg 103:853-868, 2005

56. Millauer B, Wizigmann-Voos S, Schnurch H, Martinez R, Moller NP, Risau W, et al: High affinity VEGF binding and developmental expression suggest Flk-1 as a major regulator of vasculogenesis and angiogenesis. Cell 72:835-846, 1993

57. Morita K, Matsuzawa H, Fujii Y, Tanaka R, Kwee IL, Nakada $\mathrm{T}$ : Diffusion tensor analysis of peritumoral edema using lambda chart analysis indicative of the heterogeneity of the microstructure within edema. J Neurosurg 102:336-341, 2005

58. Mukhopadhyay D, Tsiokas L, Sukhatme VP: Wild-type p53 and v-Src exert opposing influences on human vascular endothelial growth factor gene expression. Cancer Res 55:6161-6165, 1995

59. Nathoo N, Barnett GH, Golubic M: The eicosanoid cascade: possible role in gliomas and meningiomas. J Clin Pathol 57:6-13, 2004

60. Nielsen S, Nagelhus EA, Amiry-Moghaddam M, Bourque C, Agre P, Ottersen OP: Specialized membrane domains for water transport in glial cells: high-resolution immunogold cytochemistry of aquaporin-4 in rat brain. J Neurosci 17:171-180, 1997

61. Nishikawa R, Cheng SY, Nagashima R, Huang HJ, Cavenee WK, Matsutani M: Expression of vascular endothelial growth factor in human brain tumors. Acta Neuropathol 96:453-462, 1998

62. Ostergaard L, Hochberg FH, Rabinov JD, Sorensen AG, Lev M, Kim L, et al: Early changes measured by magnetic resonance imaging in cerebral blood flow, blood volume, and blood-brain barrier permeability following dexamethasone treatment in patients with brain tumors. J Neurosurg 90:300-305, 1999

63. Papadopoulos MC, Saadoun S, Davies DC, Bell BA: Emerging molecular mechanisms of brain tumor oedema. $\mathbf{B r} \mathbf{J}$ Neurosurg 15:101-108, 2001

64. Papadopoulos MC, Saadoun S, Woodrow CJ, Davies DC, Costa-Martins P, Moss RF, et al: Occludin expression in microvessels of neoplastic and non-neoplastic human brain. Neuropathol Appl Neurobiol 27:384-395, 2001 
65. Pietsch T, Valter MM, Wolf HK, von Deimling A, Huang HJ, Cavenee WK, et al: Expression and distribution of vascular endothelial growth factor protein in human brain tumors. Acta Neuropathol 93:109-117, 1997

66. Plate KH, Breier G, Weich HA, Risau W: Vascular endothelial growth factor is a potential tumor angiogenesis factor in human gliomas in vivo. Nature 359:845-848, 1992

67. Portnow J, Suleman S, Grossman SA, Eller S, Carson K: A cyclooxygenase-2 (COX-2) inhibitor compared with dexamethasone in a survival study of rats with intracerebral 9L gliosarcomas. Neuro-oncol 4:22-25, 2002

68. Provias J, Claffey K, delAguila L, Lau N, Feldkamp M, Guha A: Meningiomas: role of vascular endothelial growth factor/ vascular permeability factor in angiogenesis and peritumoral edema. Neurosurgery 40:1016-1026, 1997

69. Reulen HJ, Graham R, Spatz M, Klatzo I: Role of pressure gradients and bulk flow in dynamics of vasogenic brain edema. J Neurosurg 46:24-35, 1977

70. Reulen HJ, Huber P, Ito U, Groger U: Peritumoral brain edema. A keynote address. Adv Neurol 52:307-315, 1990

71. Reulen HJ, Tsuyumu M, Tack A, Fenske AR, Prioleau GR: Clearance of edema fluid into cerebrospinal fluid. A mechanism for resolution of vasogenic brain edema. J Neurosurg 48:754-764, 1978

72. Roberts WG, Palade GE: Neovasculature induced by vascular endothelial growth factor is fenestrated. Cancer Res 57:765-772, 1997

73. Ruderman NB, Hall TC: Use of glucocorticoids in the palliative treatment of metastatic brain tumors. Cancer 18:298-306, 1965

74. Saadoun S, Papadopoulos MC, Davies DC, Krishna S, Bell BA: Aquaporin-4 expression is increased in oedematous human brain tumors. J Neurol Neurosurg Psychiatry 72:262-265, 2002

75. Samoto K, Ikezaki K, Ono M, Shono T, Kohno K, Kuwano M, et al: Expression of vascular endothelial growth factor and its possible relation with neovascularization in human brain tumors. Cancer Res 55:1189-1193, 1995

76. Sarntinoranont M, Chen X, Zhao J, Mareci TH: Computational model of interstitial transport in the spinal cord using diffusion tensor imaging. Ann Biomed Eng 34:1304-1321, 2006

77. Schuuring J, Bussink J, Bernsen HJ, Peeters W, van Der Kogel AJ: Irradiation combined with SU5416: microvascular changes and growth delay in a human xenograft glioblastoma tumor line. Int J Radiat Oncol Biol Phys 61:529-534, 2005

78. Senger DR, Galli SJ, Dvorak AM, Perruzzi CA, Harvey VS, Dvorak HF: Tumor cells secrete a vascular permeability factor that promotes accumulation of ascites fluid. Science 219: 983-985, 1983

79. Shapiro WR, Hiesiger EM, Cooney GA, Basler GA, Lipschutz LE, Posner JB: Temporal effects of dexamethasone on bloodto-brain and blood-to-tumor transport of 14C-alpha-aminoisobutyric acid in rat C6 glioma. J Neurooncol 8:197-204, 1990

80. Shibata S: Ultrastructure of capillary walls in human brain tumors. Acta Neuropathol 78:561-571, 1989

81. Shinonaga M, Chang CC, Suzuki N, Sato M, Kuwabara T: Immunohistological evaluation of macrophage infiltrates in brain tumors. Correlation with peritumoral edema. J Neurosurg 68:259-265, 1988

82. Shweiki D, Itin A, Soffer D, Keshet E: Vascular endothelial growth factor induced by hypoxia may mediate hypoxia-initiated angiogenesis. Nature 359:843-845, 1992

83. Speirs V, Boyle-Walsh E, Fraser WD: Constitutive co-expression of estrogen and progesterone receptor mRNA in human meningiomas by RT-PCR and response of in vitro cell cultures to steroid hormones. Int J Cancer 72:714-719, 1997

84. Stadlbauer A, Ganslandt O, Buslei R, Hammen T, Gruber S, Moser E, et al: Gliomas: histopathologic evaluation of changes in directionality and magnitude of water diffusion at diffusiontensor MR imaging. Radiology 240:803-810, 2006

85. Stewart PA, Hayakawa K, Farrell CL, Del Maestro RF: Quantitative study of microvessel ultrastructure in human peritumoral brain tissue. Evidence for a blood-brain barrier defect. J Neurosurg 67:697-705, 1987

86. Stewart PA, Hayakawa K, Hayakawa E, Farrell CL, Del Maestro RF: A quantitative study of blood-brain barrier permeability ultrastructure in a new rat glioma model. Acta Neuropathol 67:96-102, 1985

87. Streffer JR, Bitzer M, Schabet M, Dichgans J, Weller M: Response of radiochemotherapy-associated cerebral edema to a phytotherapeutic agent, H15. Neurology 56:1219-1221, 2001

88. Strugar J, Rothbart D, Harrington W, Criscuolo GR: Vascular permeability factor in brain metastases: correlation with vasogenic brain edema and tumor angiogenesis. J Neurosurg 81: 560-566, 1994

89. Takamoto T, Sasaki M, Kuno T, Tamaki N: Flk-1 specific kinase inhibitor (SU5416) inhibited the growth of GS-9L glioma in rat brain and prolonged the survival. Kobe J Med Sci 47: 181-191, 2001

90. Tjuvajev J, Kolesnikov Y, Joshi R, Sherinski J, Koutcher L, Zhou Y, et al: Anti-neoplastic properties of human corticotropin releasing factor: involvement of the nitric oxide pathway. In Vivo 12:1-10, 1998

91. Uematsu H, Maeda M, Itoh $\mathrm{H}$ : Peritumoral brain edema in intracranial meningiomas evaluated by dynamic perfusionweighted MR imaging: a preliminary study. Eur Radiol 13: 758-762, 2003

92. Villalona-Calero MA, Eckardt J, Burris H, Kraynak M, FieldsJones S, Bazan C, et al: A phase I trial of human corticotropinreleasing factor (hCRF) in patients with peritumoral brain edema. Ann Oncol 9:71-77, 1998

93. Watanabe M, Tanaka R, Takeda N: Magnetic resonance imaging and histopathology of cerebral gliomas. Neuroradiology 34:463-469, 1992

94. Wei D, Wang L, He Y, Xiong HQ, Abbruzzese JL, Xie K: Celecoxib inhibits vascular endothelial growth factor expression in and reduces angiogenesis and metastasis of human pancreatic cancer via suppression of $\mathrm{Sp} 1$ transcription factor activity. Cancer Res 64:2030-2038, 2004

95. Wrba E, Nehring V, Chang RC, Baethmann A, Reulen HJ, Uhl E: Quantitative analysis of brain edema resolution into the cerebral ventricles and subarachnoid space. Acta Neurochir Suppl 70:288-290, 1997

96. Zangari M, Anaissie E, Stopeck A, Morimoto A, Tan N, Lancet J, et al: Phase II study of SU5416, a small molecule vascular endothelial growth factor tyrosine kinase receptor inhibitor, in patients with refractory multiple myeloma. Clin Cancer Res 10:88-95, 2004

Manuscript submitted February 21, 2007.

Accepted April 1, 2007.

Address reprint requests to: Walter Stummer, M.D., Department of Neurosurgery, University of Düsseldorf, Moorenstrasse 5, 40225 Düsseldorf, Germany. email: stummer@uni-duesseldorf.de. 